\title{
An Audit of Renal Clinical Pharmacist Provided Drug Information Services to Nephrology Department
}

\author{
Sathvik Belagodu Sridhar ${ }^{1 *}$, Shoukath Ali Khan, Manjunath S Shetty ${ }^{2}$ \\ ${ }^{1}$ Department of Clinical Pharmacy, JSS College of Pharmacy and JSS Medical College Hospital, Mysore, india \\ ${ }^{2}$ Department of Nephrology, JSS Medical College Hospital, Mysore, India.
}

\begin{abstract}
Background: Clinical pharmacy services in various ambulatory care settings are well-defined and documented. Nevertheless, data addressing clinical pharmacist-provided drug information services to the nephrology department are very limited. The aims of our study were to evaluate the type and quality of clinical pharmacist provided drug information services to the nephrology department. Methodology: The research clinical pharmacist participated in nephrology ward rounds for six days in a week along with an academic renal clinical pharmacist. Any medication related queries requested by the nephrologists or by other healthcare nephrology members were received and attended as per the modified systematic approach for the provision of drug information. Subsequently, the feedback information was provided to the concerned enquirer. The quality of all drug information services provided was evaluated by using drug information quality assurance assessment questionnaire. Results: Overall, 97 drug information requests were received and answered during the study period. Majority of the requests $(n=72,74.22 \%$ ) were related to the management of the patient under nephrology care and good number of the requests were related to medication dosage $(n=42,43.29 \%)$ followed adverse drug reactions $(n=22,22.68 \%)$. The preponderance of the requests $(n=54,55.67 \%)$ required up to 15 minutes of search from various drug information resources and most of these requests $(n=61,62.88 \%)$ were answered verbally with the aid of single reference $(n=48,49.48 \%)$. Majority $(n=62)$ of the drug information requests were graded as excellent. Conclusion: Our study confirms the promising role of a renal pharmacist in drug therapy management of really impaired patients and participation of renal clinical pharmacist in the regular ward rounds could be the main reason for both good number and quality of drug information provided.
\end{abstract}

Key words: Drug Information, Clinical Pharmacist, Renal Pharmacy, Quality Assurance, Pharmaceutical Care.

\section{INTRODUCTION}

The concept of clinical pharmacy practice was evolved in the mid-1960s with the aim of providing pharmaceutical care services. ${ }^{1}$ One of the initial pharmaceutical care services that were provided at that period by the pharmacist was therapeutic drug monitoring. ${ }^{2,3}$ However, at present the pharmaceutical care services are extended to medication order review, drug information, medication utilization review, monitoring and reporting of adverse drug reactions (ADRs), drugdrug interactions, provision of patient education and medication counseling. ${ }^{4-6}$

Provision of drug information for better patient care is one of the important key activities of clinical pharmacy services. Earlier studies have documented the effectiveness of drug information services provided by the clinical pharmacists to the physicians resulting in better patient care. ${ }^{7,8}$

Clinical pharmacy opportunities and services in various ambulatory care settings are well- defined and documented. ${ }^{9-12}$ Nevertheless, data addressing clinical pharmacistprovided drug information services to the nephrology department are very limited.

Since its establishment in the year 1997, July, the department of clinical pharmacy is continuously providing pharmaceutical care services including drug information ser-
DOI: 10.5530/ijopp.7.4.7

Address for correspondence: Prof. BS Sathvik Associate Professor, Department of Clinical Pharmacy \& Pharmacology, RAKCollege of Pharmaceutical Sciences,

RAKMedical and Health Sciences University,

Ras AI Khaimah, UAE

sathvikbs@rediffmail.com

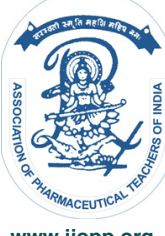

www.ijopp.org 
vices to various specialties of JSS Medical college hospital, Mysore, India. Department of clinical pharmacy at JSS hospital is a part of JSS college of Pharmacy, which has been providing pharmaceutical care services to various specialties of the hospital on a regular basis or as and when it is needed. ${ }^{13}$

The department of nephrology provides specialized care for 200 patients including dialysis and renal posttransplant care. The nephrology team consists of two senior nephrologists, one postgraduate medical student attached to nephrology unit, and one medical resident.

Although the drug information services to nephrology department are being provided since the establishment of clinical pharmacy department at JSS medical college hospital, no research work has been carried out on quality drug information services provided to the nephrology department. For the effective functioning of any clinical pharmacy department it is vital to evaluate its quality of pharmaceutical care services on a regular basis. ${ }^{14,16}$ This not only facilitates in understanding the significance and quality of the services provided by the department but also is valuable for the development of strategies to strengthen and improve the quality of the pharmaceutical care services being provided. ${ }^{17,18}$ Hence, it was felt necessary to evaluate the drug information services provided to the nephrology department and its quality independently.

The objectives of our study was to evaluate the type and quality of clinical pharmacist-provided drug information services provided to the nephrology unit of JSS Hospital, Mysore.

\section{MATERIALS AND METHODS}

As a part of clinical pharmacy services, an academic clinical pharmacist (SBS) has been posted to the department of nephrology since the year 2003 to provide regular renal pharmaceutical care services including drug information services and to train postgraduate pharmacy practice students in the area of renal pharmacy. The present study, evaluates the drug information services provided to nephrology department by the pharmacists during the year 2007 April to 2008 April.

Along with the existing academic renal clinical pharmacist (SBS), a postgraduate research clinical pharmacy student (AS) was posted to the nephrology department in the year 2007, April. The postgraduate research clinical pharmacy student participated in ward rounds for six days in a week (On an average three hour per day) along with the academic renal clinical pharmacist. Any medication/treatment-related queries requested by the nephrologists or by other members of the renal healthcare team (nurses, medical interns and postgraduate medical students) during the pre-rounds, ward rounds and post-rounds were received and documented in drug information query documentation form. Any medication-related information provided to the patients was excluded from the study.

The query was attended as per the modified systematic approach for the provision of drug information ${ }^{19}$ and the feedback information was provided to the concerned enquirer. Prior to the provision of drug information, it was reviewed by a senior academic renal clinical pharmacist or other academic clinical pharmacists of the clinical pharmacy department.

The details of drug information provided were documented in a suitably designed drug information documentation form. Consequently, a panel comprising of three academic and practicing clinical pharmacists who were not part of this study evaluated the quality of documented drug information queries (from the year 2007, April to 2008, April) using the drug information quality assurance assessment questionnaire. ${ }^{20}$ The quality of drug information provided was graded based upon the scores obtained. Grade A was considered as excellent, Grade B as good, Grade C as can improve and Grade D as should improve. The study was approved by the Institutional Ethics Committee of JSS College of Pharmacy, Mysore, India.

\section{RESULTS}

Over all 97 drug information queries were received and answered during the study period by the renal clinical pharmacists. Of these, majority of the requests were related to medication dosages $(n=42,43.29 \%)$ followed by queries regarding ADRs ( $\mathrm{n}=22,22.68 \%)$ of medications and drug administration $(\mathrm{n}=6,6.18 \%)$. Different categories of drug information requests received during the study period are presented in Table 1.

\section{Table 1: Type of drug information requests}

\begin{tabular}{ll} 
Type of drug information requests & $\begin{array}{l}\text { Number of requests } \\
\text { (N=97) }\end{array}$ \\
\hline Administration & $06(6.18 \%)$ \\
ADR & $22(22.68 \%)$ \\
Availability + Cost & $05(5.15 \%)$ \\
Dosage & $42(43.29 \%)$ \\
Drug Therapy & $02(2.06 \%)$ \\
Indication & $05(5.15 \%)$ \\
Interactions & $05(5.15 \%)$ \\
Others & $03(3.09 \%)$ \\
Pharmacokinetics & $04(4.12 \%)$ \\
Poisoning & $01(1.03 \%)$ \\
Pregnancy & $02(2.06 \%)$ \\
\hline
\end{tabular}

Indian Journal of Pharmacy Practice, Vol 7, Issue 4, Oct-Dec, 2014 
Table 2: Classification of drug information queries

Classification

No. of DIs (\%)

$\mathrm{N}=97$

\section{Requestor's identity}

* Senior Nephrologists

$62(63.91 \%)$

* Medical post graduate student

$14(14.43 \%)$

* Medicine resident

$11(11.34 \%)$

* Nurses

$09(9.27 \%)$

* Others

$01(1.03 \%)$

Mode of request

* During Ward rounds

$84(86.59 \%)$

* Through Telephone

$10(10.30 \%)$

* Direct visit to clinical pharmacy department

$03(3.09 \%)$

Reason for the drug information requests

* Update self-knowledge

$22(22.68 \%)$

* Management of the patient

$72(74.22 \%)$

* Others

$03(3.09 \%)$

Time Spent for searching answers for DI requests

* Up to 15 minutes

$54(55.67 \%)$

* 15 to 30 minutes

$20(20.61 \%)$

* 30 to 60 minutes

$13(13.40 \%)$

* 1 - 2 hours

$09(9.27 \%)$

* 2 - 4 hours

01(1.03\%)

Method of delivery of responses

* Verbal

$61(62.88 \%)$

* Written/typed

$06(6.18 \%)$

* Verbal + written/typed

$27(27.83 \%)$

* Printed material

$03(3.09 \%)$

Number of references used for searching answers

* One

$48(49.48 \%)$

* Two

$41(42.26 \%)$

* Three

$07(7.21 \%)$

* More than three

$01(1.03 \%)$

\section{Requestor's identity}

Of the 97 drug information requests received, the maximum number $(\mathrm{n}=62,63.91 \%)$ of the requests were from the senior nephrologists $(n=62,63.91 \%)$ followed by postgraduate medical students ( $n=14,14.43 \%)$. Particulars of the requestor's identity are presented in Table 2.

\section{Mode of drug information request}

Majority of the drug information were received during the ward rounds ( $\mathrm{n}=84,86.59 \%)$ followed by requests through telephone $(n=10,10.30 \%)$, Table 2.

\section{Reason for the drug information request}

Majority of the requests ( $\mathrm{n}=72,74.22 \%$ ) were directly related to the management of the patient followed by requests to update the self-knowledge ( $\mathrm{n}=22,22.68 \%$ ).
Different reasons for the drug information requests are presented in Table 2.

Amount of time spent for searching answers for the drug information request

The majority of the requests $(\mathrm{n}=54,55.67 \%)$ required up to 15 minutes of search from various drug information resources to find the answer. The details of time spent for searching the answers for the various drug information queries are presented in Table 2.

\section{Method of delivery of responses}

A good number of drug information requests $(n=61$, $62.88 \%$ ) were answered verbally to the requestor followed by both verbal and written method $(\mathrm{n}=27$, $27.83 \%$ ), Table 2 .

\section{Number of references used for searching answers for drug information request}

Most of the drug information requests were answered by searching a single database or reference $(n=48$, $49.48 \%$ ) followed by two ( $n=41,42.26 \%$ ). The number of references used for answering drug information requests is presented in Table 2.

Type of references used for searching answers for drug information request

To answer majority of the drug information queries we referred Lexi-Comp's drug information handbook followed by Micromedex. Different types of references used for answering DI requests are listed in Table 3.

\section{Quality assurance of drug information requests}

The quality of all the drug information requests received and answered during the study period were audited and graded based upon the scores obtained. Majority of the drug information requests ( $\mathrm{n}=62)$ were graded as excellent. The results of the quality assurance auditing are shown in Figure 1.

\section{DISCUSSION}

During our study period, a total of 97 drug information requests were received and answered. The number of drug information requests received was higher when compared to previous Indian study in which only 25 drug information queries were reported from the nephrology department over the span of 11 months. ${ }^{21}$ The number of drug information requests was also higher when compared to another study conducted by Devi and colleagues in the nephrology ward, which documented 28 drug information queries from nephrologists over a period of five months. However, the preceding study was aimed at evaluation of patient specific drug infor- 
Table 3: List of references used for answering the drug information queries

\begin{tabular}{|c|c|}
\hline Type of Resources & Number of requests $(\mathrm{N}=97)$ \\
\hline $\begin{array}{l}\text { Lexi-Comp's Drug } \\
\text { Information Hand Book }\end{array}$ & $39(40.20 \%)$ \\
\hline Micromedex & $31(31.95 \%)$ \\
\hline $\begin{array}{l}\text { Meyler's Side effects of } \\
\text { drugs } 18(18.55 \%) \text { Lexi- } \\
\text { comp's Pediatric Dosage } \\
\text { Hand Book }\end{array}$ & $15(15.46 \%)$ \\
\hline $\begin{array}{l}\text { lowa Drug Information } \\
\text { Service (IDIS) }\end{array}$ & $12(12.37 \%)$ \\
\hline $\begin{array}{l}\text { American Hospital } \\
\text { Formulary Service (AHFS) } \\
\text { Drug Information }\end{array}$ & $10(10.30 \%)$ \\
\hline $\begin{array}{l}\text { British National Formulary } \\
\text { (BNF) }\end{array}$ & $06(6.18 \%)$ \\
\hline Stockley's Drug Interaction's & $05(5.15 \%)$ \\
\hline $\begin{array}{l}\text { Australian Medicines Hand } \\
\text { Book (AMH) }\end{array}$ & $04(4.12 \%)$ \\
\hline $\begin{array}{l}\text { Martindale: The complete } \\
\text { drug reference }\end{array}$ & $04(4.12 \%)$ \\
\hline $\begin{array}{l}\text { Briggs' Drugs in Pregnancy } \\
\text { and Lactation }\end{array}$ & $02(2.06 \%)$ \\
\hline Merck manual & $02(2.06 \%)$ \\
\hline Others (Websites) & $07(7.21 \%)$ \\
\hline
\end{tabular}

mation needs of physicians treating diabetic nephropathy in the nephrology ward and majority of the drug information queries were received from treating physicians when compared to nephrologists $(65 \%$ vs $35 \%){ }^{22}$ In addition, the increased number of drug information requests in our study could be due to easy availability and accessibility of clinical pharmacists in the nephrology ward on a daily basis. Secondly, our study included queries related to all categories of patients who were referred to nephrology care including dialysis and posttransplant patients.
It is eminent that physician or doctors utilize the drug information services most of the time when compared to other healthcare professionals. ${ }^{23}$ Furthermore, several previously published studies have shown that treating physicians utilized most of the drug information services followed by medicine postgraduates. ${ }^{20-22,24}$ These findings were found to be similar to the findings of the present study where in most of the drug information requests received were from the treating nephrologists followed by medicine postgraduates posted to the nephrology wards. We observed in our study that nephrologists were involved in making decision about the drug therapy for most of the patients. Hence, this could be the reason for higher number of drug information requests received from nephrologists.

The majority of the drug information requests were received during ward rounds, signifying the ward rounds participation as a best opportunity for clinical pharmacists to receive medication-related queries. It was also observed in our study that numbers of drug information requests received from nurses was minimal. On the contrary, Lustig and co-workers documented nurses as the most frequent drug information seekers after physicians. ${ }^{23}$ The reason for this could be that in most of the instances nephrologists were primarily involved in making drug therapy decision than the nurses and most of the nurses posted to the nephrology unit appeared to be less aware about the services offered by the clinical pharmacist. Furthermore, regular change in the posting of the nurses could be another reason contributing for less time to develop professional rapport with pharmacist to discuss any drug- related issues.

It was not surprising to know that majority of the drug information requests received were related to treatment of the patient. Our findings were found to be in line with the results obtained in a previous study conducted by Rahman et al., in which majority of drug information requests received were related to better patient care. ${ }^{25}$

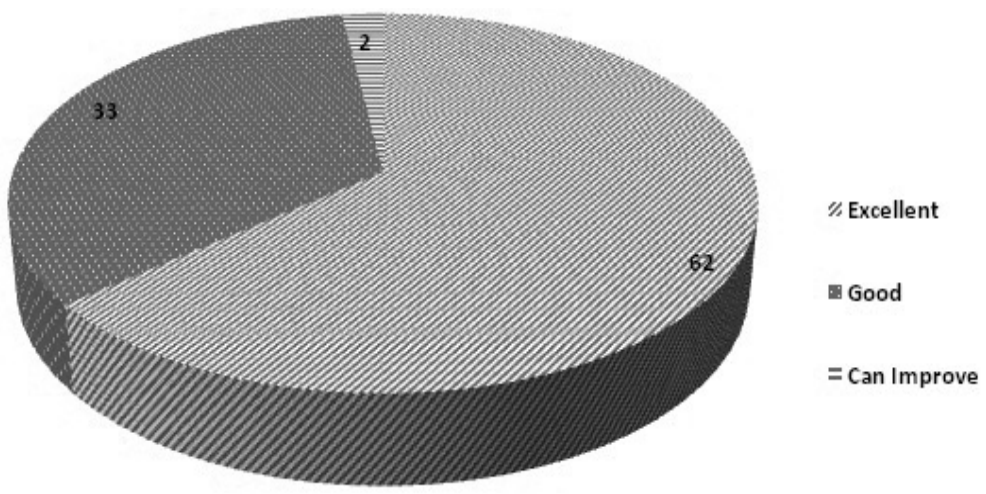

Figure 1: Quality of drug information answers 
Renal impairment is commonly observed in the patients admitted to the nephrology department and hence these patients require frequent dosage adjustment based upon the glomerular filtration rate (GFR) as most of the drugs are eliminated through kidneys. Previously published study has shown that administration and dosage are the most frequently inquired drug information queries. ${ }^{23}$ In the present study, higher number of drug information requests was related to dosage followed by ADRs. On the contrary, study conducted by Devi et al., in the nephrology ward demonstrated higher number of ADRs and drug interaction-related queries followed by drug and dosage modification. This little difference in the observation could be due to the difference in the inclusion criteria of the study. ${ }^{22}$

Majority of the drug information requests received necessitated up to 15 minutes of literature search to retrieve the answers. Our findings were found to be akin with the results obtained in previous studies, which reported that majority of the drug information requests were answered within 15 minutes. ${ }^{12-14}$ Most of the drug information queries were received during the regular ward rounds that required immediate answer for the better patient care. Interestingly, most of these queries were answered during the ward rounds due to the expected nature of the queries such as dosage of the medication based on the creatinine clearance, administration of drugs or ADRs.

Most of the drug information requests were answered verbally. Our findings were found to be similar to the results of previous study in which it was observed that the responses for the majority of the drug information requests were provided through verbal mode. ${ }^{15}$ It was noticed in our study that drug information requests received were simple in nature related to either dosage of medications or ADRs that could be verbally answered and, which really did not necessitate to be provided in the written format.

In this study, majority of the drug information requests were answered by referring to only one source of information. Our findings were found to be analogous with results observed in the previous published study in which it was concluded that a small number of tertiary sources of information were adequate to provide answers for the drug informationrequests. ${ }^{14}$ Most of the drug information requests received were related to dosage adjustment for which only one standard reference was sufficient. However, in some instances although only one reference was adequate to answer the drug information enquiry, we preferred to refer more than one reference so as to cross-check the information with an intention to provide well-referred and unbiased information to the inquirer. We referred Drug Information Hand Book for majority of the queries especially for dosage-related queries; other studies have also documented it as the most commonly referred drug information resource used by pharmacists. ${ }^{21,26}$

\section{Quality assurance of drug information requests}

Drug information request form was filled immediately after providing an answer to the enquirer. After the study period, retrospectively all the documented drug information forms were evaluated for its significance by a panel as mentioned in our study methodology.

In this study, we observed that greater number drug information requests were graded as excellent. The reasons for this could be attributed to several factors such as greater part of the drug information requests were simple in nature related to dosage or ADRs of the medications. Secondly, the background information was thorough and appropriate in almost all the cases as the pharmacist was reviewing all the inpatient case notes and following all the patients on a regular basis. Furthermore, in most instances, the drug information was reviewed by the senior clinical pharmacist(s) before providing it to the requestor. The drug information documentation form was always checked and countersigned by the academic pharmacist before and after the provision of drug information.

The main highlight of our study is that all the drug information responses provided by the pharmacists were audited for its quality, unlike selecting a random few for auditing. Moreover, same pharmacists (AS and SBS) were engaged in receiving, answering, documenting and follow-up of all the drug information requests.

Finally, this study is not free from limitations. The quality of drug information was evaluated by an internal panel contributing some bias towards the quality of drug information provided. We did not compare the data obtained against the data obtained prior to the study period.

\section{CONCLUSION}

Our study findings clearly indicates that drug information queries pertaining to dosage and adverse effects of medications requiring immediate answer were commonly received by the clinical pharmacist during the ward rounds. The present study confirms the promising role of a renal pharmacist in drug therapy management of renally impaired patients. In addition, participation of renal clinical pharmacist in the regular ward rounds could be the main reason for both good number and quality of drug information provided. 


\section{ACKNOWLEDGEMENTS}

Our Sincere thanks to Ms. Shobha Churi and Ms. Savitha RS, Lecturers and Clinical Pharmacists of department of Clinical Pharmacy, JSS college of Pharmacy and JSS Medical College Hospital for their kind help during the quality assurance of drug information services. We also sincerely thank the Head of the Department of Clinical Pharmacy services, JSS College of Pharmacy and JSS
Medical College Hospital for their kind co-operation during the study. We are also grateful to the Medical Superintendent, JSS Medical College Hospital and the Principal, JSS College of Pharmacy for their support in this study. We also extend our thanks to all the staff of nephrology department, JSS Medical College Hospital for their help and co-operation during the study period.

\section{REFERENCES}

1. Helper CD, Strand LM. Opportunities and responsibilities in pharmaceutical care. Am J Hosp Pharm. 1999; 47(3): 533-42.

2. Kaboli PJ, Angela B, McClimon BJ, Schnipper JL. Clinical pharmacists and inpatient Medical Care. Arch Intern Med. 2006: 166(09): 955-64.

3. Destache CJ, Meyer SK, Bittner MJ, Hermann KG. Impact of a clinical pharmacokinetic service on patients treated with amino glycosides: a cost benefit analysis. Ther Drug Monit 1990; 12(5): 419-26.

4. Zolezzi. The role of the clinical pharmacist in the care of renal transplant patients. Saudi J Kidney Dis Transplant 2002; 13(1): 14-7.

5. Alderman CP. A brief analysis of clinical pharmacy interventions undertaken in an Australian teaching hospital. J Qual Clin Prac. 2001; 21(4): 99-103.

6. Grade DW, Low CL, Bailie GR, Eisele G. Evaluation of drug-related problems in an outpatient haemodialysis unit and the impact of a clinical pharmacist. Clinical Nephrology 1997; 47(2): 117-21.

7. Hawkey CJ, Hodgson S, Norman A, Daneshmend TK, Garner ST. Effect of reactive pharmacy intervention on quality of hospital prescribing. $\mathrm{Br}$ Med $\mathrm{J}$. 1990; 300(6730): 986-90.

8. Merritt GJ, Garnett WR, Eckel FM. Analysis of a hospital-based drug information center. Am J Hosp Pharm. 1977; 34(1): 42-6.

9. Shah S, Dowell J, Greene S. Evaluation of clinical pharmacy services in a Hematology/Oncology outpatient setting. Ann Pharmacother 2006; 40(09): 1527-32.

10. Hatoum HT, Witte KW, Hutchinson RA. Patient care contributions of clinical pharmacists in four ambulatory care clinics. Hosp Pharm. 1992; 27(3): 203-6, 208-9.

11. Dooley MJ, Allen KM, Doecke CJ, Galbraith KJ, et al. A prospective multicentre study of pharmacist initiated changes to drug therapy and patient management in acute care government funded hospitals. Br J Clin Pharmacol. 2004; 57(4): 513-21.

12. Kaboli PJ, Hoth AB, McClimon BJ, Schnipper JL. Clinical pharmacists and inpatient medical care: a systematic review. Arch Intern Med. 2006; 166(9): 955-64.

13. Parthasarathi G, Ramesh M, Nyfort-Hansen K, Nagavi BG. Clinical pharmacy in a South Indian teaching hospital. Ann Pharmacother. 2002; 36(5): 927-32.
14. Edlund M, Harwood D. A quality assurance program for clinical pharmacy services provided to a long-term care unit in a community hospital. Can J Hosp Pharm. 1986; 39(5): 119-24.

15. Rodriguez LR, Weber C. Practical approaches to quality assurance of clinical pharmacy programs: a review. Top Hosp Pharm Manage.1988; 7(4): 24-34.

16. Tierney M, Godbout L, Repchinsky C. A peer review quality assurance program in drug information. Can J Hosp Pharm. 1991; 44(1): 31-4.

17. Thompson DF, Heflin NR. Quality assurance in drug information and poison centers: a review. Hosp Pharm. 1985; 20(10): 758-60.

18. Helper CD. Clinical pharmacy, pharmaceutical care, and the quality of drug therapy. Pharmacotherapy 2004; 24(11): 1491-8.

19. Kirkwood CF, Kier KL. Modified systematic approach to answering questions. In: Malone PM, Kier KL, Stanovich JE, eds. Drug Information Guide for Pharmacists, $3^{\text {rd }}$ ed. New York, NY;McGraw-Hill; 2006. 29-37.

20. Nibu P, Ramesh M, Parthasarathi G. Review of drug information service in an Indian teaching hospital. Aust J Hosp Pharm 2001; 31(2): 144-5.

21. Beena G, Padma Rao GM. Assessment and evaluation of drug information services provided in a South Indian teaching hospital. Indian J Pharmacol. 2005; 37(5): 315-9.

22. Devi $P$, George J. Drug information needs of physicians treating diabetic nephropathy in a tertiary care hospital. Kathmandu Univ Med Journal. 2008; 6(1): 23-7.

23. Lustig A. Experience with recently introduced drug information service in an Israeli introduced hospital pharmacy. Pharm world Sci. 1999; 21(1): 32-4.

24. Morrow NC, D'Arcy PF, Pielou LW. Drug information inquiries-who asks and where are the answers. J Clin Hosp Pharm. 1984; 9(4): 321-31.

25. Rahman $A B$, Samah Noor. The drug information service at a university hospital in Malaysia: Characteristics of drug inquiries. Drug Inf J. 1998; 32(1): 293-8.

26. Wong PS, Ko Y, SKlar GE. Identification and Evaluation of Pharmacists' Commonly Used Drug Information Sources. Ann Pharmacother. 2009; 43(2): 347-52. 